\title{
Endotoxin exposure and atopic sensitization in adult pig farmers
}

\author{
Lützen Portengen, $\mathrm{PhD},{ }^{\mathrm{a}}$ Liesbeth Preller, $\mathrm{PhD},{ }^{\mathrm{b}}$ Martin Tielen, $\mathrm{PhD},{ }^{\mathrm{c}}$ Gert Doekes, $\mathrm{PhD}{ }^{\mathrm{a}}$ \\ and Dick Heederik, $\mathbf{P h D}^{\mathbf{a}}$ Utrecht and Zeist, The Netherlands
}

Background: Recent studies have reported a low prevalence of atopic sensitization and respiratory allergy in children growing up on farms.

Objectives: We sought to evaluate the dose-response relationship between endotoxin and atopic sensitization in adult farmers and to assess the effect on respiratory health outcomes.

Methods: Data on endotoxin exposure and serum IgE levels were available for 162 pig farmers from a cross-sectional case-control study, with case selection on the basis of respiratory symptoms. Exposure to endotoxin was modeled in detail, and respiratory health effects were assessed during a medical examination. Exploratory analysis was done by using nonparametric modeling and was followed by classical parametric regression.

Results: IgE to one or more common allergens was detected in sera from $28(17 \%)$ farmers. The average (geometric mean) total serum IgE levels was $37 \mathrm{IU} / \mathrm{mL}$ (geometric SD, $4 \mathrm{IU} / \mathrm{mL}$ ). A strong inverse relationship was found between endotoxin and sensitization to common allergens for exposures of $75 \mathrm{ng} / \mathrm{m}^{3}$ or less, with an odds ratio of $0.03(95 \%$ CI, 0.0-0.34) for a 2-fold increase in endotoxin. For endotoxin exposure of greater than $75 \mathrm{ng} / \mathrm{m}^{3}$, the association was weak (odds ratio, $1.2[95 \%$ CI, 0.38-3.6]). No association was found between endotoxin exposure and total serum IgE levels. Endotoxin was associated with increased airway hyperresponsiveness to histamine and lower lung function in sensitized farmers, without evidence of a nonlinear relationship.

Conclusions: The prevalence of atopic sensitization in adult pig farmers is low. Endotoxin or related exposures might protect from sensitization, even in an adult working population exposed to high levels of endotoxin, but is a risk factor for increased airway hyperresponsiveness and low lung function. (J Allergy Clin Immunol 2005;115:797-802.)

Key words: Endotoxins, hypersensitivity, IgE, allergens, adult, occupational exposure, epidemiology

From ${ }^{a}$ the Institute for Risk Assessment Sciences (IRAS) and ${ }^{c}$ the Department of Herd Health and Reproduction, University of Utrecht, and ${ }^{\mathrm{b}}$ Food and Chemical Risk Analysis, TNO Chemistry, Zeist.

Supported by grant no. 99.33 from the Dutch Asthma Foundation (L. Portengen).

Received for publication November 11, 2003; revised November 29, 2004 ; accepted for publication November 30, 2004.

Available online February 10, 2005.

Reprint requests: Lützen Portengen, $\mathrm{PhD}$, Institute for Risk Assessment Sciences (IRAS), Utrecht University, PO Box 80176, 3508 TD, Utrecht,

The Netherlands. E-mail: L.Portengen@iras.uu.nl. 0091-6749/\$30.00

(C) 2005 American Academy of Allergy, Asthma and Immunology doi:10.1016/j.jaci.2004.11.046
Abbreviations used

AHR: Airway hyperresponsiveness

OR: Odds ratio

Recent epidemiologic studies have reported a considerably lower prevalence of atopic sensitization and symptoms of respiratory allergy in children, young adolescents, and even adults growing up on farms when compared with their peers living in the same rural areas. ${ }^{1}$ Contact with livestock during the first year of life was identified as the factor that best explained the protective effect on atopic sensitization, ${ }^{2,3}$ which is consistent with the view that early life is a critical period for initiation of allergic immune responses and asthma. ${ }^{4}$ It has been speculated that respiratory exposure to endotoxin (particularly in livestock farming) might be important. ${ }^{5}$ Several studies have shown that animal keeping is associated with exposure to high levels of bacterial endotoxin. ${ }^{6-8}$ There are strong indications that endotoxin exposure might cause or aggravate respiratory symptoms, ${ }^{9-12}$ but experimental studies have shown that timing might be crucial. Consequently, studies on the possible protective effect of endotoxin exposure have focused almost exclusively on early childhood exposure. ${ }^{13-16}$

Some studies have indicated that rural living ${ }^{17}$ or being a farmer ${ }^{18}$ is associated with a reduced risk of atopy and atopic disease in adulthood as well, and we have shown earlier that growing up on a farm and current farming were independently associated with a lower prevalence of atopic sensitization. ${ }^{19}$ Only one study has investigated the separate effects of having been born on a farm and current endotoxin exposure. ${ }^{13}$ Having been born on a farm was associated with a reduced risk of sensitization in schoolage children, but there was an additional protective effect of current endotoxin exposure.

It is not clear whether adult farmers also have a reduced risk of atopic sensitization, whether this is associated with their endotoxin exposure, and whether this has an effect on respiratory health outcomes. We therefore analyzed these relationships in a study among pig farmers. Exposure to endotoxin was measured on more than one occasion and used to model average long-term exposure. Earlier analyses have shown that high endotoxin exposure was associated with increased respiratory symptoms and 
airway hyperresponsiveness (AHR) to histamine and with lower lung function in sensitized farmers. ${ }^{20,21}$ The relationship between endotoxin exposure and atopic sensitization was not studied in detail, although it was apparent that the prevalence of sensitization to common allergens in the population was low. We analyzed the relationship between exposure to endotoxin and atopic sensitization and assessed the effect on respiratory health outcomes.

\section{METHODS}

\section{Population and health data}

Data were from a cross-sectional survey in pig farmers conducted in the early 1990s. A detailed description of the design and methods of data collection have been reported previously. ${ }^{20,21}$

The population consisted of 194 pig farmers living in the 2 southeastern provinces of the Netherlands, which were selected from a group of 1133 male owners of pig farms who worked at least 5 hours per day in pig farming. Selection was based on chronic respiratory symptoms reported in the Dutch version of a self-administered shortened questionnaire on respiratory symptoms of the British Medical Research Council. ${ }^{22}$ All farmers $(n=94)$ with more than one symptom of chronic cough, chronic phlegm, ever or frequent wheezing, shortness of breath, and chest tightness (asthma) were included, and a group of 100 control subjects was selected at random from the symptom-free farmers. In a subsequent medical survey held in winter 1990-1991, venous blood samples were taken for IgE analysis. The medical ethical committee of the University Nijmegen approved the study. Subjects received information about the trial and consented to participate in writing.

\section{IgE measurements}

Sera were stored at $-20^{\circ} \mathrm{C}$ until $\mathrm{IgE}$ analysis. Total $\operatorname{IgE}$ and specific $\operatorname{IgE}$ antibodies to the common allergens house dust mite, grass pollen (mix of 2 species), birch pollen, and cat were measured by means of enzyme immunoassays. ${ }^{23}$

Allergen-specific IgE was assessed with 1:10 diluted sera in allergen-coated microwells. A serum was considered positive if the optical density at $492 \mathrm{~nm}$ exceeded the mean optical density $+3 \mathrm{SD}$ of the reagent blank (no serum control). Total serum IgE levels were measured by means of sandwich enzyme immunoassay with sera diluted 1:10, 1:20, and 1:40, and the IgE standard for the Pharmacia CAP system was used as a calibration standard. ${ }^{23}$

\section{Lung function and AHR}

Forced expiratory lung function measurements were conducted with a Vicatest V dry rolling seal spirometer (Mijnhardt, Bunnik, The Netherlands). Measurements were performed according to the lung function protocol of the European Community for Steel and Coal. ${ }^{24}$

Airway responsiveness was tested by using histamine provocation according to a modified procedure of the method of Cockroft et al. ${ }^{25}$ Histamine concentration ranged from 0.03 to $16 \mathrm{mg} / \mathrm{mL}$. AHR was defined as a decrease in $\mathrm{FEV}_{1}$ of at least $10 \%$ at a histamine concentration of $16 \mathrm{mg} / \mathrm{mL}$ or less. ${ }^{26}$

\section{Exposure measurements and modeling}

Personal inhalable dust samples were taken twice: once in the summer and once in the winter. Dust was collected by using PAS6 sampling heads and $1-\mu \mathrm{m}$ Teflon filters (Millipore, Billerica, Mass) at an airflow of $2 \mathrm{~L} / \mathrm{min} .{ }^{6}$ Samples were stored at $-20^{\circ} \mathrm{C}$ until extraction. Endotoxin was extracted in $0.05 \%$ ( $\mathrm{vol} / \mathrm{vol}$ ) Tween 20 in pyrogen-free water and stored at $-20^{\circ} \mathrm{C}$ until analysis. ${ }^{27}$ Endotoxin levels were measured with the Lymulus Amebocyte Test, according to procedures described earlier. ${ }^{27}$ Endotoxin units were converted to nanograms of endotoxin by using a factor of $0.1 \mathrm{ng} / \mathrm{EU}$.

Endotoxin levels were expressed in nanograms per cubic meter. On the basis of the relationship between endotoxin concentration and farm characteristics and time spent on activities in pig farming during 2 full weeks, the long-term time-weighted average exposure to endotoxin was estimated. ${ }^{28}$ Estimation was based on log-transformed exposure levels to standardize variance and obtain normally distributed residuals. The measurements in the summer and winter were used as independent observations because the correlation between them was low. The final model included outdoor temperature, 12 farm characteristics, and 8 activities in pig farming and explained 37\% (adjusted $R^{2}=33 \%$ ) of the variation in log-transformed timeweighted average endotoxin exposure. In this article endotoxin exposure is defined as modeled individual long-term average exposure to endotoxin.

\section{Data analysis}

IgE sensitization to common allergens was defined as a positive reaction to one or more common allergens. Endotoxin exposure and total IgE levels were best described by using a log-normal distribution. Total IgE levels were either log transformed or dichotomized by using $100 \mathrm{IU} / \mathrm{mL}$ as a cutoff level. For exploratory analysis, the relationship between log-transformed endotoxin exposure and sensitization to common allergens, (log-transformed) total $\operatorname{IgE}$, and respiratory outcomes was studied by means of generalized additive modeling (smoothing) with PROC GAM (SAS for Windows version 8.0; SAS Institute, Cary, NC). ${ }^{29}$ For dichotomous response variables, a logistic model was used, and smoothed curves were computed by using a logit-link function and transformed to prevalences by applying the inverse of the logit function. The smoothness of the function was determined by means of generalized cross-validation. ${ }^{30}$

On the basis of results from this analysis, log-transformed endotoxin exposure was used in multiple regression analysis by using more conventional parametric models. A $P$ value of less than. 05 was considered statistically significant.

\section{Role of the funding source}

The sponsor of the study had no role in study design, data collection, data analysis, data interpretation, or writing of the report.

\section{RESULTS}

\section{Subject characteristics, atopic sensitization, and total IgE levels}

Complete data on endotoxin exposure, personal characteristics, and serology were available for 81 cases and 81 control subjects. Subject characteristics, IgE sensitization, and respiratory health outcomes in the study population stratified by case-control status are presented in Table I. Cases were somewhat older, smoked more often, and had been working with pigs for a longer time than control subjects.

Specific IgE to at least one of the 4 common allergens was detected in $28(17 \%)$ farmers and was weakly associated with case-control status (odds ratio [OR], 1.4 [95\% CI, 0.63-3.3]). Most sensitized farmers had IgE to house dust mite $(61 \%)$ or grass pollen $(36 \%)$; only $5(18 \%)$ were sensitized to birch pollen, and none were sensitized to cat allergen. Four (14\%) subjects were sensitized to more than one allergen. The average (geometric mean) total 
serum IgE level was $37 \mathrm{IU} / \mathrm{mL}$ (geometric SD, $4 \mathrm{IU} / \mathrm{mL}$ ) and was slightly higher in cases than in control subjects.

AHR was present in 50 (31\%) of 159 farmers and was strongly associated with case-control status (OR, 4.1 [95\% CI, 2.0-8.5]). Average lung function was slightly higher than predicted on the basis of age- and height-corrected reference values in control subjects, whereas $\mathrm{FEV}_{1}$ was somewhat less than predicted in cases.

\section{Endotoxin exposure and allergic sensitization}

Endotoxin exposure was similar for cases and control subjects and ranged from 36 to $316 \mathrm{ng} / \mathrm{m}^{3}$ (Table I). No significant association was found between endotoxin exposure dichotomized at the median level of $101 \mathrm{ng} / \mathrm{m}^{3}$ and specific sensitization (OR, 0.88 [95\% CI, 0.34-2.3]) or increased levels (>100 IU/mL) of total IgE (OR, $1.2[95 \%$ CI, 0.53-2.6]) in logistic regression analysis adjusting for age and current smoking, as reported earlier. ${ }^{21}$

In contrast, the OR for a 2-fold increase in exposure and sensitization to common allergens was 0.44 (95\% CI, $0.19-0.98$ ) when log-transformed endotoxin exposure was included as a continuous covariate. The shape of the doseresponse relationship was studied in more detail by using nonparametric models (smoothing). Results from this analysis suggested a significant nonlinear relationship between endotoxin exposure and sensitization to one ore more common allergens (Fig 1). Risk of sensitization strongly decreased with increasing exposure from a predicted $70 \%$ at the lowest exposure to $20 \%$ at an exposure of $75 \mathrm{ng} / \mathrm{m}^{3}$ and remained virtually unchanged for even higher exposures. We therefore allowed for different regression coefficients for endotoxin exposure less than and greater than the level of $75 \mathrm{ng} / \mathrm{m}^{3}$ in classical logistic regression analysis, including age, current smoking, and case-control status as potential confounders. This brokenstick model fitted the data significantly better than a model without a breakpoint (likelihood ratio $\chi^{2}=5.8, P=.02$ ). The results confirmed the strong inverse relationship between endotoxin exposure and sensitization to common allergens for exposures of up to $75 \mathrm{ng} / \mathrm{m}^{3}$ with an estimated OR of 0.03 (95\% CI, 0.0-0.34) for a 2-fold increase in endotoxin. For endotoxin exposure of greater than $75 \mathrm{ng} / \mathrm{m}^{3}$, the association was weak and not statistically significant (OR, 1.2 [95\% CI, 0.38-3.6]). Inclusion of a familial history of atopy or disinfectant use as potential confounders had only minor effects on these estimates, and no evidence was found for effect modification by either case-control status or current smoking in a stratified analysis.

Inspection of the dose-response curve for endotoxin exposure and sensitization to individual allergens suggested that the effect of endotoxin was strongest for sensitization to pollen, whereas there was little effect on sensitization to house dust mite (Fig 2). The small number of sensitized subjects did not allow any further detailed analysis.

Only a weak positive association was found between log-transformed endotoxin exposure and log-transformed total $\mathrm{IgE}$ levels (estimated coefficient $\beta[\mathrm{SE}]=0.19$
TABLE I. Subject characteristics, IgE sensitization, and respiratory health outcomes in pig farmers with and without chronic respiratory symptoms

\begin{tabular}{lcc}
\hline & $\begin{array}{c}\text { Control subjects, } \\
\text { n (\%)/mean (SD) }\end{array}$ & $\begin{array}{c}\text { Cases, } \\
\text { n (\%)/mean (SD) }\end{array}$ \\
\hline $\mathrm{N}$ & 81 & 81 \\
Age (y) & $36(9)$ & $40(10) \dagger$ \\
Smoker & $15(19)$ & $37(46) \dagger$ \\
Former smoker & $25(31)$ & $25(31)$ \\
Pack-years & $7(11)$ & $15(15) \dagger$ \\
Years in pig farming & $13(8)$ & $16(8) \dagger$ \\
Endotoxin exposure & $105(1.4)$ & $103(1.5)$ \\
$\quad\left(\right.$ ng/m $\left.{ }^{3}\right)$, GM $(\mathrm{GSD})$ & & \\
IgE to common allergens & $12(15)$ & $16(20)$ \\
$\quad \geq 1$ & $6(7)$ & $11(14)$ \\
House dust mite & $6(7)$ & $4(5)$ \\
Grass pollen & $3(4)$ & $2(2)$ \\
Birch pollen & $0(0)$ & $0(0)$ \\
Cat dander & $17(21)$ & $25(31)$ \\
Total IgE $\geq 100$ IU/mL & $31[4.0]$ & $45[3.9] \dagger$ \\
Total IgE, GM $(\mathrm{GSD})$ & $14 / 81(17 \%)$ & $36 / 78(46 \%) \dagger$ \\
AHR, /N $(\%)$ & $107(14)$ & $95(17) \dagger$ \\
FEV $(\%$ predicted) & $112(13)$ & $104(12) \dagger$ \\
FVC $(\%$ predicted) &
\end{tabular}

$G M$, Geometric mean; GSD, geometric SD; $F V C$, forced vital capacity. *Cases reported at least 1 chronic respiratory symptom (cough, phlegm, shortness of breath, wheeze, or chest tightness).

$\dagger P<.05$ compared with control subjects.

(0.30), $P=.5$ ), with no evidence for a nonlinear relationship. No association was found between endotoxin exposure and increased levels of total $\mathrm{IgE}(>100 \mathrm{IU} / \mathrm{mL})$ in logistic regression.

\section{Respiratory health effects}

Relationships between endotoxin exposure and a number of respiratory health outcomes in this population have been studied earlier in detail by using logistic and linear regression analysis. ${ }^{20,21,31}$ We used nonparametric models to investigate the shape of the dose-response relationship between endotoxin exposure and chronic respiratory symptoms, AHR, and lung function, adjusting for age, smoking habits, and standing height (lung function only). Endotoxin exposure was associated with increased AHR and lower $\mathrm{FEV}_{1}$ but not with the presence of chronic respiratory symptoms (Fig 3). The relationship between endotoxin and forced vital capacity was very similar to that for endotoxin and $\mathrm{FEV}_{1}$ and is therefore not shown. Associations were stronger for sensitized than nonsensitized farmers, although the interaction between endotoxin and sensitization was statistically significant only for AHR (Table II). No evidence was found for any nonlinear doseresponse relationships.

\section{DISCUSSION}

Only $17 \%$ of the full-time pig farmers in this study were sensitized to one or more common allergens. This is considerably lower than the prevalence of $32 \%$ reported for male subjects aged 20 to 70 years in the general Dutch 


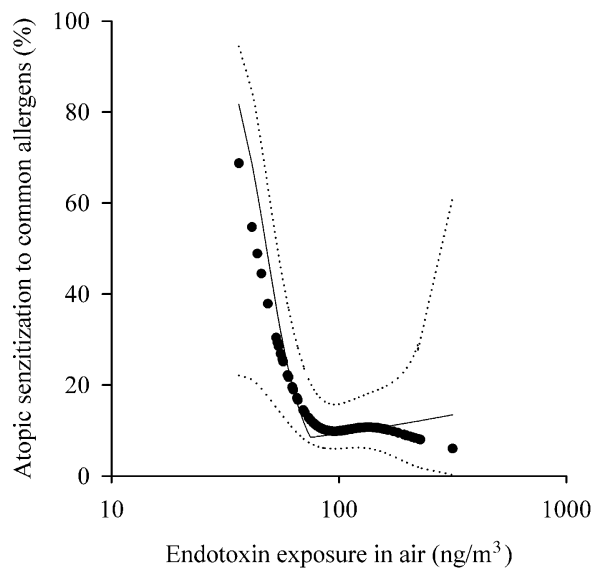

- Non-parametric model (smooth) "Broken-stick" model $95 \%$ S.E. bands

FIG 1. Inhalatory endotoxin exposure and IgE to common allergens in Dutch pig farmers: smoothed (cubic spline) plot with pointwise \pm 2 SE bands and fitted broken-stick model.

population $^{32}$ and also lower than prevalences of $27 \%$ to $38 \%$ reported in studies in other occupational groups in which the same IgE assays were used. ${ }^{33-35}$ Exposure to endotoxin was associated with a strongly reduced risk of sensitization for exposures of up to $75 \mathrm{ng} / \mathrm{m}^{3}$ but did not seem to have an additional effect at higher exposures.

There was no indication that the inverse relationship between endotoxin and IgE sensitization had an effect on the relationship between endotoxin and respiratory health effects in this population, even though dose-response curves between endotoxin and respiratory outcomes were steeper in sensitized farmers. Dose-response curves for endotoxin and respiratory symptoms, AHR, and lung function all showed a monotonically increasing risk with higher endotoxin exposures, both in stratified and nonstratified analyses. This could be due to the low number of sensitized farmers in the study and the generally weak association between $\operatorname{IgE}$ sensitization and respiratory outcomes in this population.

Our results suggest that work-related exposure to endotoxin (or associated factors) rather than lifestyle factors explains the different prevalence of atopic sensitization in farmers and nonfarmers and that exposure to endotoxin protects against atopic sensitization, even in adults. Severe confounding by differences in lifestyle factors in this study seems unlikely because all subjects were full-time pig farmers from the same general geographic area. The correlation between lifestyle factors and occupational endotoxin exposure is therefore expected to be much lower than in studies comparing farmers and farm children with rural control subjects. Confounding by childhood farm exposures is also unlikely because virtually all farmers will have been born on a farm, and the correlation between occupational endotoxin exposure and early-life exposures is therefore expected to be low. Information regarding childhood exposure was not available for this

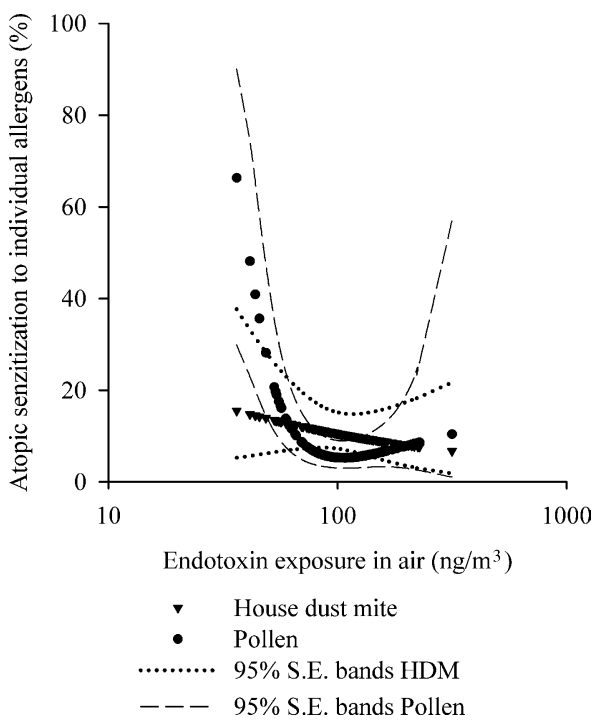

FIG 2. Inhalatory endotoxin exposure and $\lg E$ to pollen and house dust mite in Dutch pig farmers: smoothed (cubic spline) plots with pointwise \pm 2 SE bands.

study, but more than $95 \%$ of pig farmers participating in a recent study in the same general geographic area indicated they had been born on a farm (not published).

Although lifestyle factors can probably be ruled out, endotoxin might still be a surrogate marker for exposure to other agents of microbial or animal origin. ${ }^{36}$ The most important determinants of modeled exposure were activity patterns involving (close) contact with animals and flooring characteristics, ${ }^{28}$ and these are probably not very specific for endotoxin.

Because of the cross-sectional design of the study, it is impossible to say whether the low prevalence of atopy in highly exposed farmers is a consequence of a reduced incidence or an increased remission of sensitization. The fact that the effect of endotoxin might be attributed to current exposure in adults suggests the latter process could be involved.

For individual allergens, endotoxin had a stronger effect on sensitization to grass pollen than on sensitization to house dust mite, which is consistent with the results from other studies in farm children and farming adults. ${ }^{18,37-39}$ That we did not find an association between endotoxin exposure and total IgE levels could be considered inconsistent with an effect on atopic sensitization, but others have argued that total IgE levels are more strongly hereditary and less influenced by environmental factors. ${ }^{40}$

Major limitations of this study are the small population size and the fact that the study was designed to identify risk factors for chronic respiratory disease. Endotoxin exposure could be modeled for only 162 farmers, and half of these had been selected on the basis of rather general, but not work-related, respiratory symptoms. However, there was no evidence that the design had a major effect on the results because the relationship between endotoxin exposure and sensitization was similar for patients and control subjects. The allergen panel we used to define 


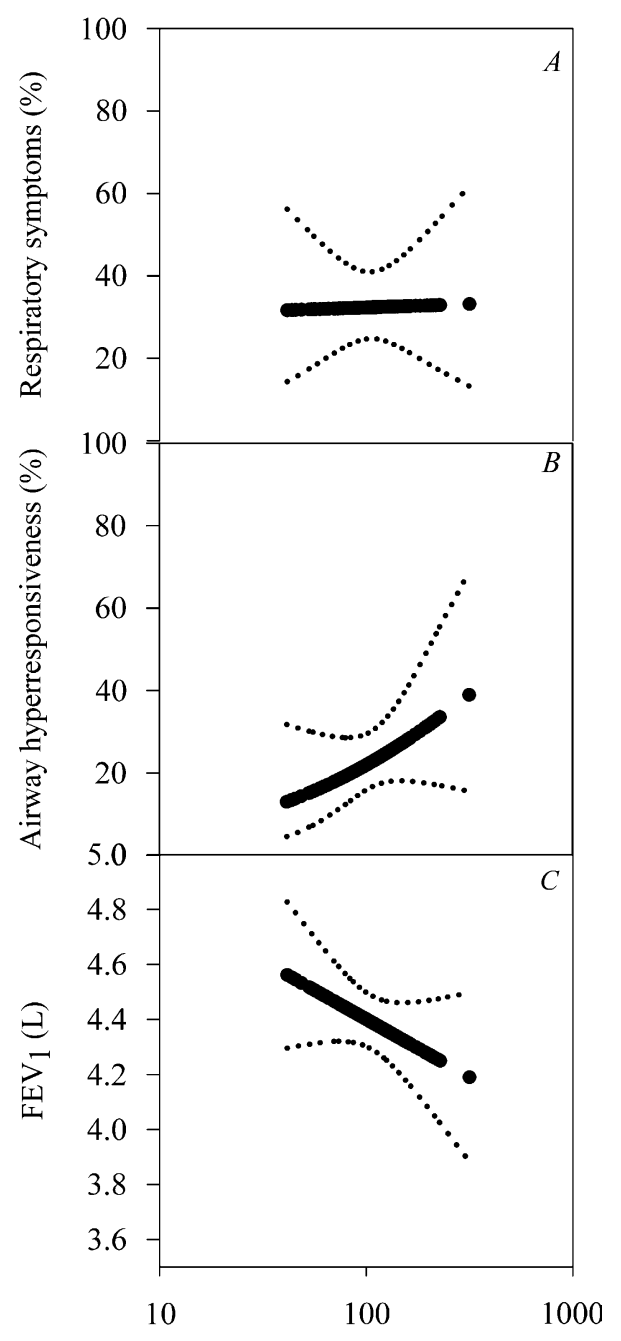

Endotoxin exposure in air $\left(\mathrm{ng} / \mathrm{m}^{3}\right)$

- Non-parametric model (smooth) ...... 95\% S.E. bands

FIG 3. Inhalatory endotoxin exposure and chronic respiratory

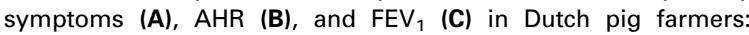
smoothed (cubic spline) plots with pointwise \pm 2 SE bands.

atopic sensitization did not include dog allergens. This is unlikely to have affected our results because sensitization to dog allergens is generally even less common than sensitization to cat allergens, and we did not find a single farmer with $\operatorname{IgE}$ to cat allergens.

The assay that was used was based on an in-house protocol. However, it had previously been validated against skin prick test results in a series of 116 children's serum samples. ${ }^{27}$ Sensitivity and specificity of the enzyme immunoassay results as a predictor of skin prick test reactivity toward common allergens were greater than $80 \%$ to $90 \%$. The assay has also been used extensively in other epidemiologic studies. ${ }^{33,34,41}$

Misclassification of exposure or IgE status could have occurred but has probably been nondifferential and would have led to underestimation of the exposure response
TABLE II. Association between endotoxin exposure and respiratory health effects in pig farmers

\begin{tabular}{|c|c|c|c|c|}
\hline Outcome & Population & $\mathbf{N}$ & Effect & $P$ value \\
\hline & & & OR $(95 \% \mathrm{CI})$ & \\
\hline \multirow{4}{*}{$\begin{array}{l}\text { Respiratory } \\
\text { symptoms }\end{array}$} & All & 162 & $1.0(0.55$ to 1.9$)$ & .9 \\
\hline & Not sensitized & 134 & $1.1(0.54$ to 2.3$)$ & .8 \\
\hline & Sensitized & 28 & $1.5(0.33$ to 6.9$)$ & .6 \\
\hline & & & OR $(95 \%$ CI $)$ & \\
\hline \multirow[t]{4}{*}{ AHR } & All & 158 & $1.6(0.79$ to 3.4$)$ & .19 \\
\hline & Not sensitized & 132 & $1.2(0.56$ to 2.7$)$ & .6 \\
\hline & Sensitized & 26 & 17 (1.3 to 227$)$ & .03 \\
\hline & & & 及 $(95 \%$ CI $)$ & \\
\hline \multirow[t]{3}{*}{$\mathrm{FEV}_{1}$} & All & 157 & $-127(-313$ to 60$)$ & .18 \\
\hline & Not sensitized & 130 & $-80(-292$ to 133$)$ & .5 \\
\hline & Sensitized & 27 & $-220(-619$ to 180$)$ & .3 \\
\hline
\end{tabular}

relationship. One of the goals of exposure modeling was to reduce misclassification by increasing the number of repeated exposure estimates per individual because pig farmers usually stick to a weekly working schedule, with considerable variation between days of the week.

Healthy worker selection could be a more serious problem because the relationship between endotoxin exposure and sensitization would be seriously biased when those with allergic symptoms (and IgE) avoid exposure to endotoxin. However, only one subject reporting (nonwork-related) allergic symptoms was exposed at endotoxin levels of $75 \mathrm{ng} / \mathrm{m}^{3}$ or less, and a strong relationship between endotoxin and sensitization was also found in those not reporting any symptoms.

Confounding by age, smoking habits, and case-control status has been taken into account in the present analysis, but other potential confounders, such as familial history of atopy, history of allergic symptoms in childhood, use of disinfectants, and number of years working with pigs, were all considered. From the difference between our and earlier reported findings, ${ }^{21}$ it is clear that the cutoff value that is chosen for the logistic regression analysis is important. Our cutoff of $75 \mathrm{ng} / \mathrm{m}^{3}$ was based on the results of an exploratory nonparametric model that clearly indicated a nonlinear relationship between endotoxin exposure and sensitization. However, use of simple logistic regression with log-transformed modeled endotoxin exposure as a continuous covariate also resulted in a very low estimated OR for endotoxin and sensitization to common allergens. Therefore the cutoff of $101 \mathrm{ng} / \mathrm{m}^{3}$ that was chosen for the earlier analysis is clearly suboptimal.

In conclusion, average long-term endotoxin exposure was associated with a reduced prevalence of sensitization to common allergens in a highly exposed adult farming population but was a risk factor for increased AHR and lower lung function in sensitized farmers. There was no evidence that the lower risk of sensitization results in a lower risk of adverse respiratory health effects. The proinflammatory effects of endotoxin exposure might therefore outweigh the potential beneficial effect on allergic sensitization. Longitudinal studies in populations 
with a high exposure to allergens and endotoxin are needed to investigate whether the protection from sensitization has an effect on the development or severity of respiratory symptoms in populations in which allergic respiratory disease is more common and whether endotoxin might reduce pre-existing sensitization.

We thank Professor James A. Deddens of the Department of Mathematics, University of Cincinnati, for his advice on evaluating nonlinear dose-response relationships.

\section{REFERENCES}

1. Johnson CC, Alford SH. Do animals on the farm and in the home reduce the risk of pediatric atopy? Curr Opin Allergy Clin Immunol 2002;2: 133-9.

2. Riedler J, Braun-Fahrlander C, Eder W, Schreuer M, Waser M, Maisch $\mathrm{S}$, et al. Exposure to farming in early life and development of asthma and allergy: a cross-sectional survey. Lancet 2001;358:1129-33.

3. Remes ST, Iivanainen K, Koskela H, Pekkanen J. Which factors explain the lower prevalence of atopy amongst farmers' children? Clin Exp Allergy 2003;33:427-34.

4. Yabuhara A, Macaubas C, Prescott SL, Venaille TJ, Holt BJ, Habre W, et al. TH2-polarized immunological memory to inhalant allergens in atopics is established during infancy and early childhood. Clin Exp Allergy 1997;27:1261-9.

5. Braun-Fahrlander C, Lauener R. Farming and protective agents against allergy and asthma. Clin Exp Allergy 2003;33:409-11.

6. Preller L, Heederik D, Kromhout H, Boleij JS, Tielen MJ. Determinants of dust and endotoxin exposure of pig farmers: development of a control strategy using empirical modelling. Ann Occup Hyg 1995;39:545-57.

7. Simpson JC, Niven RM, Pickering CA, Oldham LA, Fletcher AM, Francis HC. Comparative personal exposures to organic dusts and endotoxin. Ann Occup Hyg 1999;43:107-15.

8. Cormier Y, Israel-Assayag E, Racine G, Duchaine C. Farming practices and the respiratory health risks of swine confinement buildings. Eur Respir J 2000;15:560-5.

9. Vogelzang PF, van der Gulden JW, Folgering H, Kolk JJ, Heederik D, Preller L, et al. Endotoxin exposure as a major determinant of lung function decline in pig farmers. Am J Respir Crit Care Med 1998;157: 15-8.

10. Schwartz DA. Does inhalation of endotoxin cause asthma? Am J Respir Crit Care Med 2001;163:305-6.

11. Liu AH. Endotoxin exposure in allergy and asthma: reconciling a paradox. J Allergy Clin Immunol 2002;109:379-92.

12. Douwes J, Pearce N, Heederik D. Does environmental endotoxin exposure prevent asthma? Thorax 2002;57:86-90.

13. Braun-Fahrlander C, Riedler J, Herz U, Eder W, Waser M, Grize L, et al. Environmental exposure to endotoxin and its relation to asthma in school-age children. N Engl J Med 2002;347:869-77.

14. Gehring U, Bischof W, Fahlbusch B, Wichmann HE, Heinrich J. House dust endotoxin and allergic sensitization in children. Am J Respir Crit Care Med 2002;166:939-44.

15. Bottcher MF, Bjorksten B, Gustafson S, Voor T, Jenmalm MC. Endotoxin levels in Estonian and Swedish house dust and atopy in infancy. Clin Exp Allergy 2003;33:295-300.

16. Bolte G, Bischof W, Borte M, Lehmann I, Wichmann HE, Heinrich J. Early endotoxin exposure and atopy development in infants: results of a birth cohort study. Clin Exp Allergy 2003;33:770-6.

17. Kauffmann F, Oryszczyn MP, Maccario J. The protective role of country living on skin prick tests, immunoglobulin $\mathrm{E}$ and asthma in adults from the Epidemiological Study on the Genetics and Environment of Asthma, Bronchial Hyper-responsiveness and Atopy. Clin Exp Allergy 2002;32: 379-86.

18. Filipiak B, Heinrich J, Schafer T, Ring J, Wichmann HE. Farming, rural lifestyle and atopy in adults from southern Germany-results from the MONICA/KORA study Augsburg. Clin Exp Allergy 2001;31:1829-38.

19. Portengen L, Sigsgaard T, Omland O, Hjort C, Heederik D, Doekes G. Low prevalence of atopy in young Danish farmers and farming students born and raised on a farm. Clin Exp Allergy 2002;32:247-53.
20. Preller L, Heederik D, Boleij JS, Vogelzang PF, Tielen MJ. Lung function and chronic respiratory symptoms of pig farmers: focus on exposure to endotoxins and ammonia and use of disinfectants. Occup Environ Med 1995;52:654-60.

21. Preller L, Doekes G, Heederik D, Vermeulen R, Vogelzang PF, Boleij JS. Disinfectant use as a risk factor for atopic sensitization and symptoms consistent with asthma: an epidemiological study. Eur Respir J 1996;9: 1407-13.

22. Biersteker DK, van Dijk WH, Eissens JB, van Geuns HA. [Inquiry into chronic non specific lung disease among the communal staff of Rotterdam during 1970 and 1971 [author's translation]. T Soc Geneesk 1974;52:158-62.

23. Doekes G, Douwes J, Wouters I, de Wind S, Houba R, Hollander A. Enzyme immunoassays for total and allergen specific IgE in population studies. Occup Environ Med 1996;53:63-70.

24. Quanjer PH, Tammeling GJ, Cotes JE, Pedersen OF, Peslin R, Yernault JC. Lung volumes and forced ventilatory flows. Report Working Party Standardization of Lung Function Tests, European Community for Steel and Coal. Official Statement of the European Respiratory Society. Eur Respir J Suppl 1993;16:5-40.

25. Cockcroft DW, Killian DN, Mellon JJ, Hargreave FE. Bronchial reactivity to inhaled histamine: a method and clinical survey. Clin Allergy 1977;7:235-43.

26. Rijcken B, Schouten JP, Weiss ST, Speizer FE, van der Lende R. The relationship of nonspecific bronchial responsiveness to respiratory symptoms in a random population sample. Am Rev Respir Dis 1987; 136:62-8.

27. Hollander A, Heederik D, Versloot P, Douwes J. Inhibition and enhancement in the analysis of airborne endotoxin levels in various occupational environments. Am Ind Hyg Assoc J 1993;54:647-53.

28. Preller L, Kromhout H, Heederik D, Tielen MJ. Modeling long-term average exposure in occupational exposure-response analysis. Scand J Work Environ Health 1995;21:504-12.

29. Hastie TJ, Tibshirani RJ. Generalized additive models. New York: Chapman and Hall; 1990.

30. Wahba G. Spline models for observational data. Philadelphia: Society for Industrial and Applied Mathematics; 1990.

31. Vogelzang PF, van der Gulden JW, Preller L, Tielen MJ, van Schayck $\mathrm{CP}$, Folgering H. Bronchial hyperresponsiveness and exposure in pig farmers. Int Arch Occup Environ Health 1997;70:327-33.

32. Kerkhof M, Droste JH, de Monchy JG, Schouten JP, Rijcken B. Distribution of total serum IgE and specific IgE to common aeroallergens by sex and age, and their relationship to each other in a random sample of the Dutch general population aged 20-70 years. Dutch ECRHS Group, European Community Respiratory Health Study. Allergy 1996;51:770-6.

33. Houba R, Heederik D, Doekes G. Wheat sensitization and work-related symptoms in the baking industry are preventable. An epidemiologic study. Am J Respir Crit Care Med 1998;158:1499-503.

34. Zock JP, Heederik D, Doekes G. Evaluation of chronic respiratory effects in the potato processing industry: indications of a healthy worker effect? Occup Environ Med 1998;55:823-7.

35. Heederik D, Venables KM, Malmberg P, Hollander A, Karlsson AS, Renstrom A, et al. Exposure-response relationships for work-related sensitization in workers exposed to rat urinary allergens: results from a pooled study. J Allergy Clin Immunol 1999;103:678-84.

36. Roy SR, Schiltz AM, Marotta A, Shen Y, Liu AH. Bacterial DNA in house and farm barn dust. J Allergy Clin Immunol 2003;112:571-8.

37. Riedler J, Eder W, Oberfeld G, Schreuer M. Austrian children living on a farm have less hay fever, asthma and allergic sensitization. Clin Exp Allergy 2000;30:194-200.

38. Leynaert B, Neukirch C, Jarvis D, Chinn S, Burney P, Neukirch F. Does living on a farm during childhood protect against asthma, allergic rhinitis, and atopy in adulthood? Am J Respir Crit Care Med 2001;164:1829-34.

39. Kilpelainen M, Terho EO, Helenius H, Koskenvuo M. Childhood farm environment and asthma and sensitization in young adulthood. Allergy 2002;57:1130-5.

40. Koppelman GH, Jansen DF, Schouten JP, van der Heide S, Bleecker ER, Meyers DA, et al. Sibling effect on atopy in children of patients with asthma. Clin Exp Allergy 2003;33:170-5.

41. Wouters IM, Hilhorst SK, Kleppe P, Doekes G, Douwes J, Peretz C, et al. Upper airway inflammation and respiratory symptoms in domestic waste collectors. Occup Environ Med 2002;59:106-12. 